\title{
Tradução e as interfaces na pesquisa
}

\author{
Meta Elisabeth Zipser ${ }^{1}$ \\ Juliana de Abreu ${ }^{2}$
}

\begin{abstract}
The wide gamut of research objects being worked in the Postgraduate Program in Translation Studies (PGET) of the Federal University of Santa Catarina (UFSC) ensures the Translation Studies field's multidisciplinarity with the different knowledge camps. Different translation interfaces considered, we draw attention to some of the research being developed in the Translation and Culture Research Group (TRAC-CNPq-UFSC), such as translation and teaching, translation and journalism, scientific papers translation, translation and gastronomy, translation and advertisement, and translation and comics. Based on Textual Analysis in Translation (NORD, 2016), and the Functionalist Translation principles (REISS, 1983; VERMEER, 1986; NORD, 1991; [1988] 2009; 2016), we display translation reaching its goal, as a communication act, that is, enabling comprehension in a new culture context, gifting the prospective reader, without missing the original characteristics. Translating in interfaces means to respect the textual genres, the cultures of origin and destination, keeping an eye the translation goals.
\end{abstract}

Keywords: translation; functionalism; culture; modern foreign languages; textual genres.

Resumo: A grande gama de objetos de pesquisa trabalhados no Programa de Pós-Graduação em Estudos da Tradução (PGET) da Universidade Federal de Santa Catarina (UFSC) assegura a interdisciplinaridade do campo dos Estudos da Tradução com as diferentes áreas do conhecimento. Considerando as diversas interfaces tradutórias, apontamos para alguns dos estudos desenvolvidos no Grupo de Pesquisa Tradução e Cultura (TRACCNPq-UFSC), como tradução e ensino, tradução e jornalismo, tradução de artigos científicos, tradução e gastronomia, tradução e publicidade e tradução de quadrinhos. Com base na Análise Textual em Tradução (NORD, 2016) e nos preceitos Funcionalistas de Tradução (REISS, 1983, VERMEER, 1986; NORD, 1991; [1988] 2009; 2016), mostramos a tradução alcançando seu objetivo, quando tratada como ato comunicativo, qual seja, viabilizando a compreensão em um novo contexto de cultura, contemplando o leitor em prospecção, sem perder as características de origem. Traduzir em interfaces significa respeitar os gêneros textuais, as culturas de partida e de chegada, sem perder de vista os objetivos tradutórios.

Palavras-chave: tradução; funcionalismo; cultura; línguas estrangeiras modernas; gêneros textuais.

1 Professora associada da Universidade Federal de Santa Catarina, UFSC. Coordena o Grupo de Pesquisa Tradução e Cultura -TRAC e desenvolve projetos de extensão voltados ao ensino de língua alemã em comunidades afins.

2 Doutoranda pelo Programa de Pós-Graduação da Universidade Federal de Santa Catarina - UFSC, e desde 2012 é membro do Grupo de Pesquisa TRAC - Tradução e Cultura. 


\section{Introdução}

Com o intuito de legitimar memórias acadêmicas, ao mesmo tempo em que se ativa e discute pesquisas realizadas, ampliando seu alcance para com o público leitor, este artigo visa compartilhar um pouco do mundo do TRAC (Grupo de Pesquisa Tradução e Cultura), trazendo à superfície aspectos interessantes de vários trabalhos aqui realizados. Escolhemos pesquisas de mestrado e doutorado defendidas entre os anos de 2005 e 2017, sob a orientação de Meta Elisabeth Zipser, no Programa de Pós-Graduação em Estudos da Tradução (PGET) da Universidade Federal de Santa Catarina (UFSC), que abordam gêneros textuais diversos, os quais apresentam pontos de encontro - aqui denominados de interfaces - trabalhados no universo da tradução.

A base teórica dentro dos Estudos da Tradução que apresentamos nesse artigo é sempre funcionalista, em conversa com as teorias guia das várias interfaces, ancoradas nos trabalhos das orientandas, as quais estão sempre identificadas pelo nome e período de realização da pesquisa.

A apresentação de cada uma das interfaces se dá pelo critério cronológico, ou seja, da mais antiga para a mais recente. Quando mais de uma pesquisa faz parte de uma interface específica, sua localização fica definida a partir da primeira pesquisa do grupo. Os pares de línguas trabalhados são alemão, espanhol, francês, inglês e português lusitano, quase todos contrastados com o Português brasileiro. As pesquisas entre 2005 e 2017 estão disponíveis em sua forma completa no site da Biblioteca da UFSC ${ }^{1}$ ou no site PGET $^{2}$.

Segundo Vermeer (1986), o próprio termo "traduzir algo" já deveria nos alertar e conduzir ao questionamento do fato de como seria possível partir de um texto concreto, manter sua forma, conteúdo quando a tradução implica levarmos esse texto para outra língua, outra cultura e outro público e ainda garantir a comunicação efetiva? Quais seriam os requisitos para se realizar tarefa similar? Esclarecendo a situação e ressaltando o ato comunicativo, Vermeer (1986, p. 4) coloca:

O tradutor ou intérprete é o especialista bicultural e bilingual que garante a comunicação para além de barreiras culturais e linguísticas, por responsabilidade própria, e já não é de maneira nenhuma o subestimado, anônimo e "fiel" transmissor de palavras ou expressões que quase sempre resultam mutiladas e truncadas.

$\mathrm{Na}$ abordagem funcionalista de tradução, são ressaltados aspectos comunicativos que nos auxiliam na tarefa tradutória, a saber: para que traduzir? O que traduzir? Como traduzir? Para quem traduzir? E com que propósito (skopos) traduzir? Mantendo o enfoque nessas perguntas, automaticamente preservamos os princípios comunicativos.

Posto isso, a tradução no presente artigo não é vista apenas como um ato linguístico, mas sim como um ato comunicativo entre culturas, no qual a língua é o instrumento. $\mathrm{O}$ tradutor é, portanto, como já mencionado, um especialista intercultural.

Nord (1991, [1988] 2009; 2016), desenvolve um modelo textual voltado à tradução, que pode servir de guia seguro para tradutores, sejam novatos ou experientes. Dividido em duas partes, a primeira delas se refere aos elementos extratextuais (emissor, intenção, público, meio, lugar, tempo, motivo e função) e a segunda, aos intratextuais (assunto, conteúdo, pressuposições, estruturação, elementos não verbais, léxico, sintaxe e elementos suprassegmentais). Fechando o modelo, temos o efeito do texto, que é analisado de acordo com a função textual. Seguindo esse modelo, a tradução é trabalhada de fora (ele- 
mentos extratextuais) para dentro (elementos intratextuais), sempre considerando tudo o que ocorre "fora" do texto, seja seu contexto imediato e igualmente o contexto histórico-cultural. Uma vez visto isso, voltamo-nos aos elementos intratextuais, que movimentam o texto, dando-lhe o contorno apropriado para a nova situação, o novo leitor.

Nas interfaces trabalhadas, podemos identificar marcas claras de adequação ao novo ambiente, à nova situação, à nova cultura, quando se estuda a tradução como ato comunicativo, eficaz e pertinente. Na interface tradução-jornalismo, por exemplo, temos a seguinte situação: o jornalista relata um acontecimento que virou notícia, denominado por Zipser (2002) de fato noticioso. Para certificar-se de que esse fato noticioso chega de forma clara e compreensível para seu leitor, o jornalista-tradutor considera: o que o leitor sabe a respeito do assunto? Preciso contextualizar? Qual o nível de interesse do leitor acerca do assunto? Devo ampliar ou reduzir o relato do fato? Fatos similares acontecem na comunidade alvo? Tenho como ancorar? Caso seja possível a ancoragem na cultura alvo, inicia-se um trabalho específico, definido por Zipser (2002) como Tradução como Representação Cultural. Essa ancoragem se torna possível sempre que forem identificados elementos na cultura alvo que possam ser usados pelo jornalista para aproximar o fato noticioso - novo - ao universo do leitor.

Portanto, entendemos por Tradução como Representação Cultural os artifícios utilizados através da ancoragem sócio-histórico-cultural para aproximar o público leitor do fato noticioso. Se pensarmos esse trabalho de forma um pouco mais ampla, vemos que cabe ao jornalista, em sua função de divulgar os fatos noticiosos uma boa parcela de exercício de tradução e que essa mesma situação se repete nas demais interfaces.

Ao redigir uma propaganda, por exemplo, não seria um recurso interessante para a equipe da agência pensar em elementos inseridos na cultura alvo para aproximar seu produto do público alvo, para que a propaganda "funcione" melhor, motivando seu público a adquirir o produto? Ao relatar fatos noticiosos televisivos, o repórter não recorre a elementos locais para introduzir e contextualizar a notícia? E o livro didático, usado em sala de aula nas mãos do professor? Esse livro certamente traz eventos culturais ligados à língua estrangeira que enfoca. Se o professor não entrar com explicações adicionais a respeito desses eventos culturais, o aluno (público alvo) não apreende as sutilezas da cultura atrelada à língua que aprende. Cabe ao professor "traduzir" os elementos que cercam o evento em questão, para que o aluno possa substituir os valores e imagens que tem de sua própria cultura e assimilar os novos e, principalmente, aprender a colocá-los cada qual em seu lugar, em seu contexto, com sua língua. A mesma situação, devidamente contextualizada, se repete nas demais interfaces: receitas culinárias, artigos científicos e histórias em quadrinhos.

Assim, este artigo traz consigo um convite ao leitor para se desprender de velhos conceitos e refletir sobre a tradução como uma atividade muito mais ampla do que aquela que percebemos num primeiro momento.

\section{Tradução e jornalismo: impresso e televisivo}

A interface tradução-jornalismo é o objeto de pesquisa de doutorado de Zipser (2002), pela Universidade de São Paulo (USP). Área, na época, ainda pouco pesquisada, o trabalho foi pioneiro e poucos eram os pares que havia para eventuais diálogos.

O suporte teórico da pesquisa de Zipser (2002) é o funcionalismo de Christiane Nord (1988), com seu Modelo de Análise Textual voltado à tradução, e o trabalho do jornalista alemão, Frank Esser (1998), que desenvolveu um Modelo Pluriestratificado ${ }^{3}$, que retrata e discute as camadas de influência no jornalismo. 
Segundo Esser (1998), todo texto jornalístico está inserido em um contexto histórico-social e situacional. Por contexto histórico-social, entendemos toda a realidade de origem do país/comunidade, refere-se a um país colonizador ou colonizado, cuja a estrutura social predominante, sua história política e marcas históricas ajudam a definir os contornos do país. O contexto situacional tem a ver com o momento em que o texto é produzido, a situação econômico-social, a situação política e maior ou menor proximidade ao fato noticioso. Todos esses parâmetros ajudam a definir como o texto jornalístico é produzido e apresentado.

Em outra instância, temos ainda a influência da formação do próprio jornalista, o perfil da redação onde este trabalha, enfim, nenhum texto é isolado, isento, sempre está ligado a uma série de fatores que o determinam. Todo esse raciocínio deve ser repetido ao se transferir qualquer texto jornalístico para outro contexto, não o da sua origem, afinal teremos outro público, outra realidade histórico-social, outra redação, etc.

Ampliando um pouco esse raciocínio, vemos que a proximidade entre jornalismo e tradução é muito maior do que se imagina num primeiro momento. Para mostrar essa proximidade, trouxemos cinco trabalhos da interface tradução-jornalismo: A interface tradução e jornalismo: marcas culturais no texto de revista, (SACHET, 2005); O Mundo pós 11 de setembro: tecendo fios/textos entre a tradução e a narratividade jornalistica (POLCHLOPEK, 2011); Marcas culturais em interface: os caminhos de aproximação entre tradução e jornalismo (MAZUTTI, 2011); O caso AF447: o jornalista como tradutor de fatos nas culturas brasileira e portuguesa (AIO, 2012) e Tradução jornalística: alusões na tradução como fator cultural no texto telejornalístico (HESSMANN, 2013).

Iniciamos com Sabrina Sachet (2005) que em sua pesquisa de mestrado, fundamentada em suas leituras, afirma que

[...] é importante ressaltar que, em sua natureza, a reportagem jornalística está emoldurada por fatores que influenciam sua produção. São questões políticas, sociais, econômicas, entre outros. Esses fatores serão apresentados e identificados pelo Modelo Pluriestratificado Integrado, de Frank Esser (1998), in Zipser (2002), por meio do qual é possível reconhecer as instâncias que compõem o fazer jornalístico e fornece um panorama da sua dinâmica de atuação. Esse modelo trabalha o conceito de interculturalidade, isto é, o espaço de confronto entre duas culturas, identificando fatores que conferem ao jornalismo de cada país uma identidade nacional e cultural próprias. (SACHET, 2005, p. 13).

Com isso, Sachet (2005, p. 14) reforça que "[...] a mídia exerce influência na produção da informação e há grande possibilidade de os enfoques dos temas abordados seguirem um critério sujeito a índices de vendagem, cujo objetivo é a aceitação do público leitor."

Diante dessas constatações, a motivação da pesquisa de Sachet $(2005$, p. 14) passa por “[...] investigar quais os aspectos [são] considerados para a construção desses textos [jornalísticos], bem como de sua tradução." Para isso, quatro estratégias são traçadas: i) comprovar que os textos trazem consigo as marcas culturais de cada país; ii) demonstrar sob quais aspectos tais marcas se manifestam nos textos; iii) discutir se as escolhas realizadas pelo tradutor caracterizam um eventual deslocamento de enfoque e, por fim, iv) cooperar para a difusão dos Estudos da Tradução no ambiente jornalístico. (SACHET, 2015).

Para tanto, Sachet (2005, p. 14) faz uso de duas versões (inglês americano e português brasileiro) da revista National Geographic inseridas em culturas e línguas distintas, na tentativa de comprovar "[...] que os textos trazem consigo as marcas culturais de cada país, e que em cada cultura o texto apresenta-se de forma diferente." 
As reportagens da National Geographic selecionadas por Sachet (2005) são uma versão fonte, Saving Afghan Culture, publicada nos Estados Unidos e uma tradução da mesma, A eterna cultura afegã, publicada no Brasil. Ambas as reportagens são assinadas por Andrew Lawler, desprezando assim os tradutores da própria revista, localizados pela pesquisadora durante seu trabalho e que devem ter sido os tradutores da reportagem para a revista brasileira, informação fundamental para análise da tradução, afinal,

As diferenças na abordagem do mesmo assunto podem revelar as adequações realizadas pelo produtor da notícia, tanto ao perfil do leitor a quem se destina, quanto às questões sociais, políticas, econômicas, etc., do local ou país em que ela será apresentada. Sofrendo assim um deslocamento na perspectiva do enfoque, que tende a ocorrer na passagem de uma notícia ou reportagem de uma língua/cultura para outra. Esse eventual deslocamento de enfoque pode ser percebido, de diversas maneiras, dentre elas citamos as escolhas em relação ao título e subtítulo, às figuras, e no texto propriamente dito, com as escolhas lexicais, sintáticas, entre outros elementos que darão o direcionamento da leitura. (SACHET, 2005, p. 15).

No decorrer de sua pesquisa, Sachet (2005, p. 88-89) comprova que a aplicação dos modelos de Nord (1991) e Esser (1998) na análise das reportagens, "[...] ajuda a reconhecer a natureza das duas grandes áreas que compõem esta interface, bem como estabelecer possíveis comparações entre tradução e jornalismo [...]", afinal, os textos i) cumprem sua função quando chegam às mãos do receptor; ii) as escolhas feitas levam o texto ao seu propósito e iii) os fatores sociais e culturais influenciam na produção do texto jornalístico. (SACHET, 2005, p. 89).

Ao comparar as duas reportagens, Sachet (2005, p. 90) (re)afirma "que os textos trazem consigo as marcas culturais de cada país." Inicialmente, as reportagens aparentavam ser idênticas devido ao formato padrão da revista (mesma paragrafação, figuras, número de páginas). Porém, após análise, as marcas culturais manifestadas por meio do léxico, expressões idiomáticas, entre outras, ficaram evidentes. Logo, cada texto traz consigo as representações culturais do seu país. (SACHET, 2005).

A pesquisa de Sachet (2005) contempla a nova interface - tradução-jornalismo - apresentada por Zipser (2002), inaugurando assim um novo nicho de pesquisa na área dos Estudos da Tradução, fundamentada nas teorias de Christiane Nord (1991; [1988] 2009; 2016) e Frank Esser (1998), as quais se complementam muito bem, formando assim igualmente uma nova interface teórica.

O estudo seguinte é de Polchlopek (2011) que em seu doutorado desenvolve como tema um estudo de títulos jornalísticos publicados em jornais on-line. Para a pesquisadora, "Os títulos são compreendidos como narrativas tradutórias, culturalmente marcadas, acerca dos desdobramentos que [sucedem] os eventos [...]. Não se trata da tradução de títulos e sim dos títulos como traduções de fatos noticiosos." (POLCHLOPEK, 2011, p. 17).

Como objetivo geral da pesquisa, Polchlopek (2011, p. 30) traça a análise, diacrônica, dos títulos de reportagens on-line pós "11 de setembro", nos Estados Unidos e no Brasil, com o propósito de apurar a possível tessitura de uma nova tradução do fato. Especificando a proposta, a pesquisadora propõe as seguintes estratégias:

i) verificar se a sequencialidade dos títulos efetivamente constrói uma nova narrativa para os desdobramentos do "11 de setembro" e se esta narrativa se configura como uma possibilidade tradutória para os fatos noticiosos e ii) analisar as escolhas lexicais (verbos, substantivos e adjetivos) empregadas pelo NYT e FSP na construção dos títulos, no sentido de 
verificar se geram deslocamentos de enfoque que ressaltem marcas culturais e categorizações narrativas passíveis de configurar a narrativa como tradução culturalmente dos fatos noticiosos. (POLCHLOPEK, p. 31).

Baseada em Bakhtin (1992; 2000), Polchlopek (2011, p. 47) reconhece que

Ancorado em elementos situacionais e passíveis de compreensão pelo leitor, o texto estabelece ligações com outros textos, apresenta novos conhecimentos e gera marcas específicas da cultura para a qual é destinado, especialmente quando as notícias transitam em ambiente internacional, visto que as diferenças culturais se tornam geralmente mais sensíveis.

Ou seja, "[...] o texto dialoga com o interlocutor, provoca respostas e favorece a interação de forma semelhante ao jornalismo e a tradução". Estando assim "O significado das palavras [...] no uso, não mais na imobilidade e na arbitrariedade [...], o que significa dizer, por extensão, que tradução e jornalismo podem ser compreendidos como relações sociais mediadas pela linguagem, através do uso da palavra." (POLCHLOPEK, 2011, p. 47).

Buscando alcançar seus objetivos, Polchlopek (2011, p. 35) primeiramente faz uma coleta nos bancos de dados dos jornais analisados (Folha Online - FSP e Times. com - NYT), seguindo na organização do corpus por títulos de seção ('Mundo' e 'World') nos jornais como referência para o olhar sobre os desdobramentos do evento ocorrido em 11 de setembro de 2001, para então construir uma rede semântica para a triagem dos títulos das seções, organizar sequencialmente a temática dos títulos filtrados e, por fim, construir a narrativa e análise das escolhas lexicais.

Concluindo a análise da pesquisadora, podemos afirmar que, "[...] o título ocupa lugar de destaque no texto, além de orientar sua leitura, visto que a titulação circunstancia o fato e agrega o inusitado, o impacto da informação sobre o leitor" (POLCHLOPEK, 2011, p. 97). Isso vale tanto para notícias disponíveis na modalidade impressa, como na on-line, fechando mais uma vez com a afirmação que tradução e jornalismo são perfeitamente integrados, pois, na especificidade dessa pesquisa,"O título de um fato noticioso não deve ser visto como um elemento acessório, ele encanta e seduz de modo a concretizar a leitura da notícia. Sem o título o leitor desconhece a existência do fato." (POLCHLOPEK, 2011, p. 278).

Seguimos assim com a pesquisa de Mazutti (2011) que, como Sachet (2005), também utiliza a revista National Geographic, para o par de línguas espanhol (Espanha e América Latina) e português (Brasil). Sua busca, similar à de Sachet (2005), é mostrar quanto e como as marcas culturais individualizam as reportagens, direcionando-as ao seu público leitor específico. Para isso, a pesquisadora se utiliza de um corpus de reportagens sobre o futebol. Tema que, por si só, já vem com marcas culturais fortes.

A base teórica, Nord (1991) e Esser (1998), é enriquecida com as considerações de Mikhail Bakhtin (2004), sob a seguinte perspectiva

[...] permeando tais relações estão os signos verbais, estes signos que constituem o universo da palavra e carregam as características e ideologias da cultura daquela sociedade na qual está inserida. Cada sociedade cria e emprega seus próprios signos com características e objetivos próprios. E é também através dos signos, junto com a fala e a escrita, que cada língua se materializa. $\mathrm{O}$ indivíduo ao adquirir uma língua estará também adquirindo a ideologia e a cultura que dão base a esta, o que torna a língua suscetível de interpretação. A vida em sociedade fará com que o indivíduo construa seus pensamentos e interprete a realidade exterior e interior segundo seus padrões ideológicos. (MAZUTTI, 2011, p. 2). 
Assim sendo, Mazutti (2011, p. 11) convence seu leitor que a escrita jornalística é, na sua essência, um processo tradutório e defende em sua pesquisa que as diferenças entre as revistas fazem parte desse processo, afinal cada uma das revistas é direcionada para uma cultura e público distintos. "[...] Sabemos que apesar de se comunicarem através do mesmo idioma, o público leitor das referidas traduções está inserido em culturas diferentes, que apresentam, por exemplo, variações linguísticas, dialetos e expressões idiomáticas específicas de sociedade". (MAZUTTI, 2011, p. 12).

O próprio editorial da revista aborda em sua capa quais reportagens e fotos merecem destaque na edição mensal. Mazutti (2011, p. 45-46) evidencia que nas três reportagens analisadas por ela, publicadas em junho de 2006, as capas das três edições divergem nas imagens e nos artigos de destaque. Na edição brasileira, o foco está na imagem de Ronaldinho Gaúcho (na época era jogador destaque no âmbito brasileiro), na edição para circulação na América Latina, a imagem de uma criança cabeceando uma bola de futebol e na espanhola, a imagem de um urso polar, com destaque para uma matéria sobre o Alasca.

A pesquisadora consegue realçar que, mesmo que as línguas e culturas possam estar geograficamente próximas (no caso da revista publicada para a América Latina e Brasil), os textos são marcados para seus públicos, atendendo os princípios do ato comunicativo, que se realiza sempre que seu leitor é verdadeiramente contemplado.

O próximo trabalho é de Aio (2011) cuja pesquisa busca "identificar as diferenças de enfoque dadas a um mesmo acontecimento por revistas brasileiras e portuguesas com o intuito de analisar a relevância do fator cultural no jornalismo e na tradução".

Assim como os trabalhos até o momento citados, Nord (1991), Esser (1998) e Zipser (2002), formam o alicerce teórico do estudo de Aio (2011). Ou seja, o fazer jornalístico está atrelado à atividade tradutória quando as notícias são tidas como traduções de fatos.

Reportagens publicadas, em impressos, para as culturas portuguesa (Visão e Sábado) e brasileira (Veja e IstoÉ), sobre a queda do Airbus 330-200, ocorrida em $1^{\circ}$ de junho de 2009, constituem o tema do corpus de pesquisa de Aio (2011). Além do embasamento teórico e da análise das reportagens, algumas considerações sobre língua, enquanto manifestação cultural, são apresentadas.

Em seu estudo, Aio (2011) trata a língua Portuguesa, em suas variedades brasileira e lusitana, como duas línguas distintas devido às diferenças culturais de ambas. "Em diferentes culturas encontramos, consequentemente, diferentes línguas, próprias para as necessidades de comunicação de cada comunidade." (AIO, 2011, p. 31). E reforça afirmando que "[...] a língua com[o] um elemento atrelado à cultura, do mesmo modo que o jornalismo e a tradução têm a língua como instrumento substancial, a cultura passa a fazer parte da atividade tradutória e jornalística como ferramenta indispensável." (AIO, 2011, p. 34). Assim sendo, “[...] uma reportagem não pode abster-se de trazer em si os elementos culturais da comunidade em que se insere, estejam eles impressos no léxico ou na organização sintática da língua." (AIO, 2011, p. 34).

Ao discorrer sobre a prática do jornalista enquanto um tradutor de fatos - um dos conceitos elaborados por Zipser (2002) - Aio (2011, p. 34) reitera:

Ao tradutor cabe levar em consideração a cultura da comunidade receptora, seu modo de ver o mundo que a cerca, suas ideologias, seu passado, sua memória cultural. Os mesmos princípios são aplicáveis à atividade jornalística. A reportagem fatalmente conterá elementos pertinentes à cultura em que se inserem seus leitores. O jornalista, assim como o tradutor, geralmente pertence à mesma comunidade cultural em que estão os leitores - da reportagem e da tradução. É inevitável, portanto, que se considere a (in)formação cultural como de fundamental relevância no cumprimento de ambas as atividades. (AIO, 2011, p. 34). 
Ao tratar o jornalista como um tradutor de fatos, Aio (2011) faz uma análise comparativa de quatro reportagens publicadas em duas revistas semanais de circulação nacional no Brasil, Veja e IstoÉ, e outras duas em Portugal, Visão e Sábado, sobre o sumiço do Airbus 330-200, operado pela Air France, voo AF 447, rota Rio de Janeiro-Paris, utilizando o Modelo de Análise Textual de Nord (1991), o qual leva em consideração os elementos externos e internos dos textos analisados.

Nesses termos, na comparação das quatro reportagens, Aio (2011, p. 90) destaca que “A questão central das reportagens - o desaparecimento do avião da Air France - é representada de dois modos distintos pelas revistas brasileiras e portuguesas." Nas revistas brasileiras o fato está relacionado à segurança das aeronaves e nas revistas portuguesas aos mistérios da história da aviação mundial, confirmando mais uma vez que públicos distintos levam a enfoques também diferenciados, devido ao seu contexto desigual.

Com essa constatação, mostramos que realmente jornalismo e tradução estão muito próximos, claramente "desenhados" em seus textos impressos, modalidade até aqui analisada. Na sequência, mostramos uma análise tradutória em texto jornalístico televisivo, onde as marcas tradutórias, ancoradas na cultura, estão igualmente presentes.

Hessmann (2013) aborda o jornalismo televisivo em sua pesquisa de mestrado, sendo o coração do trabalho as representações culturais resultantes do deslocamento de enfoque feitas ao casamento real inglês, ocorrido em 29 de abril de 2011, nas reportagens francesa e brasileira. O corpus é composto das transcrições de dois textos orais televisivos, sendo o primeiro transmitido no Brasil, pela Rede Globo de Televisão, e o segundo na França, pela Rede Télévision Française 1 (TF1).

Em seu estudo, Hessmann (2013) discute a ancoragem cultural nos dois textos telejornalísticos, nas duas línguas - francês e português -, acerca do mesmo fato noticioso e do jornalista enquanto tradutor.

A pesquisadora comprova seu objetivo de pesquisa baseada na afirmação de que alusões destacadas constituem recursos discursivos elaborados e dirigidos a determinado público-alvo. Como exemplo disso, podemos mencionar a tentativa de aproximação do fato noticioso - o casamento real na corte inglesa - do público telespectador do telejornal brasileiro, ao mencionar que o "sim" dos noivos ecoa como um grito de gol e a crítica velada à (não) utilização do chapéu na cerimônia real para o público francês, conduzindo assim, à Representação Cultural de Zipser (2002). (HESSMANN, 2013, p. 85). Ou seja, “[...] as alusões encontradas nas duas reportagens telejornalísticas só encontram sentido na cultura de chegada, pois é lá o lugar em que se encontram seus telespectadores." (HESSMANN, 2013, p.87). Pois

É no interior da cultura, com as atenções voltadas para o seu público-alvo que os jornalistas e tradutores selecionam estratégias de cunho linguístico: escolhas lexicais, recursos sintáticos e semânticos, bem como usos pragmáticos e discursivos, para o desenvolvimento do seu trabalho." (HESSMANN, 2013, p. 85).

E a pesquisadora ainda reforça, "[...] na tradução não se pode mais aceitar a idéia de equivalência entre palavras e a decodificação de signos descontextualizados da cultura de chegada, no telejornalismo [...] não é [...] aceitável a idéia de "traduzir" fatos sem [...] conhecimento sociocultural do público de chegada." (HESSMANN, p. 85).

Sendo assim, Hessmann (2013, p. 86) ratifica que "Quando se comparam notícias veiculadas em países diferentes, não se está mais pondo em discussão somente fatos, mas sim componentes culturais intrínsecos e subjacentes a serem considerados." Portanto, 
"Pode-se dizer que as reportagens são traduções de fatos que se desenvolvem: textos dirigidos aos seus públicos receptores e seus contextos culturais.” (HESSMANN, 2013, p. 87).

\section{Tradução e ensino: livro didático e sala de aula}

$\mathrm{Na}$ interface tradução e ensino vemos claramente a importância do papel da cultura no processo de aprendizado. Graças à teoria funcionalista, é possível sustentar um olhar ampliado sobre o livro didático, considerando-o passível de ser adequado, nas mãos de um professor bem preparado, para uma situação que aproxime o aluno ao universo do Outro, ampliando assim seu aprendizado, que deve ir além da Língua Estrangeira (LE) em si.

Começamos então por Laiño (2010) cuja pesquisa de mestrado tem como objetivo geral a comprovação da necessidade da tradução dos elementos culturais apresentados nos textos presentes em livros didáticos destinados aos estudantes brasileiros de língua espanhola.

Para isso, pauta-se em etapas, sendo i) "analisar cinco textos propostos nos livros didáticos de Espanhol como Língua Estrangeira (ELE) e seu tratamento à cultura do Outro"; ii) "identificar os elementos culturais abordados nos textos (tradições, léxico, metáforas, expressões, etc.)"; iii) "verificar o nível de compreensão dos alunos à exposição de aspectos culturais apresentados nos textos"; iv) apurar"[...] os desdobramentos da leitura dos discentes com a presença da tradução dos aspectos culturais apresentados pelo docente em sala de aula, e por fim, v) "propor recontextualizações dos textos escolhidos como forma de suprir as necessidades do estudante para um aprendizado mais completo." (LAIÑO, 2010, p. 12).

Essas recontextualizações propostas por Laiño visam oferecer ao professor de LE uma visão diferente de como trabalhar e em que momento isso deve acontecer. Para tanto, são consideradas quatro características que auxiliam na definição do livro didático:

(1) são orientados por princípios: princípios básicos de conhecimento, segundo o modelo de teoria de linguagem adotado; (2) são metódicos: o conhecimento é dividido em itens e classificado, e a aprendizagem é seqüencial e cumulativa; (3) são autoritários: o que o livro diz é sempre verdade; (4) são literais: devem ser seguidos literalmente e possuem formas e significados literais. (KRAMSCH, 1995 apud LAIÑO, 2010).

Laiño ressalta ainda que "[...] que o livro didático funciona como uma das várias ferramentas que podem ser utilizadas pelos educadores e tem a função de mediar os caminhos entre teorias de aquisição e o professor." (KRAMSCH, 1995 apud LAIÑO, 2010, p. 14).

A autora reforça o uso do livro didático enquanto ferramenta para suas aulas, procurando desenvolver os conteúdos que se encontram nos livros, num primeiro momento pela forma como lá são abordados, atentando para a forma que o assunto é explicado e se está adequado ao público alvo. Caso não esteja, busca complementações com materiais extras para enriquecer o tema tratado no livro didático.

Dessa forma, podemos afirmar que Laiño (2010) atribui ao professor o papel de tradutor. Para reforçar essa postura, a pesquisadora evidencia que "[...] assim como traduções de obras de uma cultura fonte para uma cultura alvo demandam modificações e adaptações de cunho cultural, alguns textos de livros didáticos também as necessitam." A pesquisadora diz que tal afirmação está embasada "[...] no fato que o aluno de LE precisa ter uma aproximação adequada com a cultura do Outro e não somente aprender a língua a partir de exercícios gramaticais, o que muito é priorizado em sala de aula." (LAIÑO, 2010, p. 12). E alerta também que para 
[...] efetuar e consolidar o exercício didático, o professor deve ter a sensibilidade de, a partir do conhecimento do perfil de seus alunos, fazer as devidas adaptações nas atividades e não delegar ao livro o rumo das suas aulas. Isto é, seu trabalho em sala de aula dependerá de sua formação acadêmica, assim como seu conceito de língua estrangeira. Pode-se afirmar também, dessa forma, que o professor é, além de mediador, um tradutor. É tradutor no sentido de estar frequentemente traduzindo a cultura do Outro para seus alunos, transitando entre duas, ou mais, culturas e servindo como ponte para estabelecer um diálogo entre o aqui e o lá, entre o eu e o Outro, para que o aluno não se sinta em caminhos desconhecidos sem saber como transitar. (LAIÑO, 2010, p. 72).

Fechando as reflexões de Laiño (2010, p. 73),

O professor, então, assim como o tradutor, deve ter um conhecimento das culturas envolvidas para que seus alunos, no âmbito de seu aprendizado, obtenham um conhecimento profundo da língua e não apenas superficial, como apenas saber decodificar orações de outra língua sem compreender seu contexto sócio-cultural.

É preciso que nos conscientizemos que trabalhar com LE e sua respectiva cultura em sala de aula, na verdade, é um desafio. Há uma distância relevante entre o ambiente real, onde a LE e sua cultura acontecem, e a sala de aula. "Como já visto, [infelizmente], o livro didático, muitas vezes, não é adaptado ao público alvo sendo que seu contexto sócio-cultural não é prioridade." (LAIÑO, 2010, p. 72, grifo nosso).

A abordagem funcionalista da tradução enfatiza "[...] que se o texto for traduzido para outra língua este será utilizado por outro público diferente do texto original [...]" (LAIÑO, 2010, p. 72), ou seja, as adaptações culturais precisam ser feitas pensando em seu público alvo. Dessa forma, podemos afirmar que o professor ao fazer uso do livro didático em sala de aula, assume a postura de um tradutor de culturas, abrindo um novo mundo para seus alunos, sempre que a cultura na qual a LE que ensina estiver contemplada e for devidamente "traduzida".

Continuando a abordagem de ensino de LE e tradução, propomos a releitura do Modelo de Análise Textual, de base funcionalista de tradução de Christiane Nord (1991; 2009; 2016), por meio da pesquisa de mestrado de Melo (2012), reforçando a visão da tradução como ato comunicativo, envolvido por elementos extra e intratextuais, dentro da sala de aula.

A proposta da pesquisa de mestrado de Melo (2012) é conscientizar alunos de LE de que traduzir não é apenas passar um texto (oral ou escrito) de uma língua para outra, afinal existem fatores que envolvem o processo tradutório e que precisam ser considerados para que textos funcionais sejam criados. Para isso, Melo (2012) mostra a importância dos elementos extratextuais, com aplicações práticas com alunos do curso de Letras Espanhol da UFSC.

Melo (2012) compartilha da concepção funcionalista proposta por Nord (1991), em que a tradução é considerada uma atividade intercultural e sempre voltada ao público alvo. Nesses termos, o texto sai da posição de ser um conjunto de códigos linguísticos somente, para um universo maior, com marcas culturais próprias que o identificam, ao mesmo tempo em que o diferem de outros textos elaborados em contextos próprios.

Apesar disso,

No âmbito do ensino de línguas estrangeiras (LE), quando se aborda o tema de tradução suscita em muitos professores certo receio motivado pela imagem negativa herdada da Abordagem Gramática-Tradução, que propunha atividades mecânicas de traduzir listas de 
palavras como também textos literários. E pode ser por esta razão que muitos professores ignoram o uso da tradução em sala de aula por acreditarem que tal habilidade não é benéfica para os estudantes. (MELO, 2012, p. 17).

Na pesquisa de Melo (2012) percebe-se a defesa do uso da tradução em sala de aula, para o ensino de LE, baseada em estudos recentes na área de tradução e ensino de línguas, contrapondo a resistência de muitos profissionais em utilizar a tradução como estratégia de ensino e aprendizagem. Autores como Agra (2007), Checchia (2002), Azenha (1999) e Hinojosa e Lima (2008), selecionados por Melo (2012), ressaltam pontos favoráveis ao uso dessa habilidade em sala de aula. "Esses autores, de maneira geral, defendem que a tradução é uma atividade enriquecedora no processo de aprendizagem de uma LE, já que envolve além das habilidades de compreensão e produção de texto, o contato cultural com a língua que se estuda." (MELO, 2012, p. 38).

Com base nos autores citados, Melo (2012) destaca a importância do uso da tradução em sala de aula como uma forma de refletir as línguas enredadas no processo tradutório, as culturas, as expressões e estruturas linguísticas envolvidas no ato comunicativo, concedendo assim, certa liberdade de produção textual aos aprendizes da LE.

[...] os pressupostos do enfoque comunicativo de LE apresentam muitos pontos em comum com os pressupostos da teoria funcionalista, uma vez que ambos concebem língua e cultura como elementos indissociáveis e no momento de transmitir uma mensagem levam em consideração o contexto cultural bem como o seu ouvinte ou leitor. (MELO, 2012, p. 40).

O material de análise, do estudo de Melo (2012) é composto por traduções da língua espanhola para o português brasileiro, produzidas por estudantes das $6^{\mathrm{a}}$ e $8^{\mathrm{a}}$ fases do Curso de Graduação em Letras Espanhol da UFSC. A turma foi separada em dois grupos (A e B), sendo que o Grupo A recebeu, primeiramente, instruções sobre os aspectos tratados no modelo de Christiane Nord (1991; [1988] 2009; 2016) para produzir suas traduções e o Grupo B recebeu apenas o encargo da tradução.

A atividade prática proposta foi uma tarefa de tradução (MELO, 2012) na qual os Gru$\operatorname{pos} A$ e $B$ receberam dois textos produzidos no México, os quais deveriam ser traduzidos para o português brasileiro, pensando assim em seu leitor final. Inicialmente Melo (2012) fez dois questionamentos: i) ambos os leitores compartilham exatamente os mesmos conhecimentos prévios sobre o tema abordado nos textos? ii) a situação comunicativa de recepção desses textos pelo leitor brasileiro é exatamente a mesma do leitor mexicano? Melo (2012, p. 46) coloca que "são esses tipos de questionamentos que o aluno-tradutor deve fazer em todo o processo tradutório." São questionamentos iniciais que fazem toda a diferença no resultado final e o resultado dessa experiência foi, no mínimo, interessante.

Enquanto que o grupo que foi instruído se preocupou com seu leitor final, tentando adequar seu texto, o grupo que não recebeu nenhuma instrução simplesmente traduziu, quase que palavra-por-palavra. A riqueza do trabalho tradutório dos alunos que haviam recebido as instruções mostrou-se compensador. Produziram textos comunicativos, perfeitamente adequados à realidade do leitor brasileiro, frente ao fato ocorrido no texto original mexicano.

Com isso, Melo (2012) consegue mostrar que o aluno aprendiz de LE pode e deve trabalhar com a tradução nas aulas de LE, pois além de prazerosa, essa atividade lhe abre horizontes. O suporte da teoria funcionalista permite que o aluno se sinta mais seguro, motivado na continuidade de seu aprendizado. 
A gastronomia está em evidência na atualidade, especialmente devido ao mundo globalizado e sem fronteiras quando nos referimos ao acesso, de dentro de nossas próprias casas, a diversas culturas presentes no mundo da cozinha. Encontramos nas livrarias físicas e online grande oferta de livros receitas, traduzidos - ou não -, além da disponibilidade de diversos programas televisivos, as séries, os documentários, os filmes, sites, blogues, entre outros.

$\mathrm{O}$ ato de cozinhar faz parte das práticas cotidianas nas diferentes culturas presentes no mundo, porém a composição dos ingredientes utilizados e a manipulação dos mesmos já apresenta um fundo cultural, que podemos dizer: pertencentes a um mundo específico. Visto assim, cozinhar é cultural e o pano de fundo mostra nomeações específicas de ingredientes, pratos, modo de preparo, pesos e medidas que até mesmo numa suposta mesma língua podem não ser compreendidos.

A pesquisa de mestrado de Abreu (2014), a qual trata de receitas culinárias impressas na Alemanha e na Áustria, tem a cultura como elemento central ao justificar a necessidade da tradução intralingual, ao analisar o léxico de receitas culinárias análogas de língua alemã (variedades nacionais alemã e austríaca). A pesquisadora reconhece a língua e a alimentação como dois elementos característicos da cultura de um povo.

A base teórica do estudo de Abreu (2014), aliada ao Modelo de Análise Textual em Tradução (NORD, 2009; 2016), é formada pelos conceitos de cultura (DAMATTA, 1986; SANTOS, 2006; LARAIA, 2009), tradição (HOBSBAWN, 2012) e identidade (BAUMAN, 2005; HALL, 2011), que auxiliam na relação da proposta da Teoria de Línguas Pluricêntricas (MUHR, 2000; AMMON, 1995) voltada para a língua alemã e o gênero textual receitas culinárias (TRAVAGLIA, 1992, 2007; MARCUSCHI, 2003, 2004, 2006, 2010).

Com base nos autores citados, Abreu (2014, p. 12) considera cultura como "[...] as manifestações sociais de grupo, configuradas pelos repletos padrões comportamentais, crenças e valores formados pela história e diversidade dos modos de expressões." O mundo globalizado, no qual a abertura de fronteiras para a comercialização de produtos industrializados (roupas, móveis, carros, acessórios, entre tantos outros) tende a "padronizar as culturas", novos artifícios identitários são (re)criados para reforçar as culturas locais, retratando assim os elementos culturais associados às identidades como forma de se diferenciar e se afirmar perante outras culturas. (ABREU, 2014). A identidade cultural está ligada às "[...] diferentes maneiras de se identificar e relacionar com uma ou mais culturas, e também, como uma (re) invenção de costumes, tradições e comportamentos, consolidando assim o sujeito social em diferenciados mundos culturais." E a tradição acompanha esse mesmo movimento de (re) criações, somada, inclusive às invenções que formalmente são institucionalizadas.

Reforçar as identidades e (re)criar tradições não significa se fechar para o compartilhamento de culturas, pois é devido a troca enriquecedora das culturas que outras tradições são (re)criadas e novas identidades (re)afirmadas. Aqui podemos pensar no que é denominada culinária tradicional alemã. Ao saborear um Apfelstrudel (folhado de maçã de origem austríaca) na atualidade não é o mesmo que era saboreado há 50 anos. Hoje temos a facilidade de encontrar massa folhada na sessão de congelados do supermercado, a grande variedade das maçãs e ainda servir com uma bola de sorvete de baunilha. Não é devido às facilidades e incorporação do sorvete, que o Apfelstrudel deixou de ser uma comida típica, tradicional austríaca [ou alemã, para muitos] que representa a identidade de um povo. $\mathrm{O}$ folhado de maçã foi difundido mundialmente e reinventado para o mundo globalizado atual. 
O mesmo evento ocorre na forma como as receitas culinárias são escritas e descritas. Os gêneros textuais são "eventos textuais maleáveis, dinâmicos e plásticos" (MARCUSCHI, 2010, p. 19 apud ABREU, 2014, p. 6) e o gênero textual receitas culinárias, apesar de ser classificado como injuntivo, é caracterizado pela sua forma consolidada em três categorias esquemáticas: ingredientes, modo de preparo e dicas, além do uso predominante, em algumas culturas, do verbo no modo imperativo. É um gênero que com o passar do tempo também passa a ser (re)inventado e que sua forma "tradicional" de apresentação transforma-se dependendo do meio em que circula. Assim como as culturas e as receitas culinárias são renovadas por meio das (re)invenções das tradições e (re)criações de novas identidades, a língua também se modifica.

Retomando a comercialização do mundo globalizado, podemos aqui citar a expansão do comércio editorial tanto virtual quanto físico. A Áustria e Alemanha são países que têm a língua alemã como língua oficial. É uma suposta mesma língua, porém, por experiência própria, Abreu (2014) relata a dificuldade de encontrar ingredientes nos supermercados de Viena ao ir com a lista de compras feita com base em livros de receitas editados na Alemanha e comercializados nas livrarias austríacas. Ou seja, uma simples receita culinária não pode ser executada, não pela inexistência de algum ingrediente nas prateleiras dos supermercados austríacos, e sim pela diferença dos nomes para os mesmos produtos.

Dessa forma, para conseguir realizar uma simples compra, a tradução intralingual se fez - e ainda se faz - necessária, pois a mesma língua em países diferentes (e mesmo dentro de um próprio país) pode apresentar variedades que podem levar à incerteza, ao engano, ao erro e ao limite da não comunicação dentro da [suposta] mesma língua.

Para compreender melhor as divergências e convergências da língua alemã, linguistas alemães e austríacos desenvolveram a Teoria de Línguas Pluricêntricas. Essa teoria abrange [as supostas] mesmas línguas que são faladas em países diferentes, como alemão, francês, inglês, português, entre outras. O estudo de Abreu (2014) discorre sobre as variedades nacionais alemã e austríaca da língua alemã.

Para uma língua ser considerada pluricêntrica, inicialmente dois requisitos são básicos: i) a presença da língua em vários países e ii) o status de língua nesses países. (MUHR, 2000, p. 27 apud ABREU, 2014, p. 19). Por esses dois quesitos básicos, a língua alemã pode ser considerada uma língua pluricêntrica, pois é presente, e também reconhecida como língua oficial, em mais de um país, como por exemplo, na Alemanha, Áustria e Suíça.

Além dessas duas exigências, Muhr (2000 apud ABREU, 2014, p. 19) apresenta oito critérios específicos para uma língua ser reconhecidamente pluricêntrica. Dentre esses, o sexto critério pontua "a existência das diferenças linguísticas e comunicativas em relação às outras variedades [...].” (MUHR, 2000, p. 3-4, apud ABREU, 2014, p. 19, tradução nossa). Aqui, observamos a relação com o que já foi tratado anteriormente sobre cultura, identidade e tradição, suas especificações, (re)invenções e (re)criações. Ou seja, a língua é um meio de expor a cultura e também afirmar a identidade de uma sociedade que está em constante mudança.

Posto isto, ressaltamos que a língua alemã nesses países apresenta divergências, mas a culinária entre os países que têm o alemão como língua oficial é parecida, muitas vezes igual em seu sabor final, porém os pratos e os ingredientes apresentam nomes diferentes e a forma de preparo e unidades de medidas também são descritas de maneiras distintas, destinadas a públicos distintos, o que torna necessária uma tradução intralingual, pontual, do gênero textual receitas culinárias, tornando-as então compartilháveis.

Tratando as variedades nacionais alemã e austríaca da língua alemã, o estudo de Abreu (2014) apresenta uma análise comparativa de 18 receitas culinárias análogas, porém com títulos diferentes, publicadas em dois impressos da Alemanha e dois da Áustria. 
Ao identificar por intermédio do léxico, elementos culturais e identitários, chegou-se à conclusão de que os títulos das receitas estão ancorados no contexto sócio-histórico-cultural do país onde se encontram, o que permite uma analogia com a teoria de Tradução como Representação Cultural (ZIPSER, 2002). A forma como essas receitas estão escritas e descritas, depende de quem e para quem se escreve, ou seja, aquele que produz o texto já tem [ou deveria ter] conhecimento a respeito do público que recebe seu texto.

Sendo assim, ao levar em consideração a variedade linguística nacional e a diversidade cultural e identitária entre os dois países (Alemanha e Áustria), a tradução intralingual acaba se tornando uma prática recorrente. Com base na visão funcionalista da tradução e na proposta de um Modelo de Análise Textual para prática tradutória (NORD, 2009; 2016), os dados das receitas culinárias selecionadas evidenciam os elementos que correspondem aos fatores externos e internos ao texto, os quais ao se inter-relacionarem, proporcionam um resultado denominado efeito textual.

Abreu (2014) constata que muitas vezes o efeito do texto se realiza em partes ou não se realiza por completo, devido a alguns aspectos, como por exemplo, i) o não compartilhamento total do léxico, ou ii) no caso onde algum ingrediente não existe em um dos países, ou ainda iii) no caso de não compartilhamento parcial do léxico.

Conforme as discussões dos dados de Abreu (2014), as receitas culinárias analisadas revelam que mesmo que a língua alemã padrão seja compartilhada pela Alemanha e Áustria, quando se trata do gênero textual receitas culinárias, os elementos culturais são variáveis presentes que levam ao possível não compartilhamento da língua devido seus contextos sócio-histórico-culturais divergentes. Ou seja, a tradução intralingual faz-se completamente necessária e legítima, exercendo o papel de Tradução Cultural, pois a cultura está por trás das escolhas lexicais, das especificações de pesos e medidas, marcando a identidade cultural de cada país.

\section{Tradução e publicidade: traduzindo as Havaianas}

Natalino (2014) foca em sua pesquisa o universo publicitário confrontado com a tradução. Que tradução seria essa que, aparentemente invisível, tem papel tão importante no mundo da publicidade?

Ancorada na concepção teórica funcionalista de Nord (1991), Vermeer (1986) e Zipser (2002), Natalino (2014) se debruça sobre duas forças poderosas da nossa realidade globalizada: a publicidade e a tradução. Como vêm sendo tratado nos trabalhos aqui apresentados, Natalino (2014) legitima sua base funcionalista ao afirmar que "A tradução, vista sob o viés funcionalista, é considerada comunicação intercultural, e o tradutor, com foco no receptor, tem o papel de mediador cultural e determina as estratégias de produção textual com base nas informações obtidas a partir deste."

Diante dessa perspectiva, o estudo da pesquisadora tem por objetivo "analisar duas campanhas publicitárias da marca Havaianas, veiculadas no Brasil e nos Estados Unidos, em 2012, a fim de identificar um possível deslocamento de enfoque, observar como eles se revelam nos textos e como são percebidos no momento da recepção." (NATALINO, 2014 , p. 26). A interface tradução e publicidade tem como ponto de partida as situações comunicativas, na qual há um emissor com intenções específicas e um destinatário representando uma audiência pré-estabelecida.

Como parte integrante das estratégias de marketing empresarial, a publicidade contempla elementos semelhantes aos pensados no processo tradutório, a saber: "PARA QUE 
comunicar (objetivos); PARA QUEM comunicar (público-alvo), O QUE comunicar (conceito) e COMO comunicar." (NATALINO, 2014, p. 50-51, grifos da autora). Ou seja, "na publicidade essas informações determinam ou influenciam a estratégia de comunicação utilizada na produção dos materiais" e na tradução, essas informações estão "relacionadas ao contexto de produção e recepção do texto, que determinam as estratégias e escolhas utilizadas pelo tradutor." (NATALINO, 2014, p. 52).

Seguindo o raciocínio, Natalino (2014, p. 53) afirma que,

[...] tanto para a publicidade quanto para suas traduções é o público-alvo quem irá determinar as estratégias comunicativas para a produção textual, e, desse modo, o contexto de recepção (a situação do leitor, o meio em que o texto/anúncio aparece etc.) irá conduzir o autor/produtor desse texto a atingir seu propósito comunicativo, que pode ou não ser concretizado no momento da recepção.

A pesquisadora ainda reflete que "[...] como na tradução as informações relacionadas ao contexto de produção e recepção do texto determinam as estratégias e escolhas utilizadas pelo tradutor [...], associando que "[...] na publicidade, essas informações determinam ou influenciam a estratégia de comunicação utilizada na produção dos anúncios e das campanhas." (NATALINO, 2014, p. 96).

Em sua análise, Natalino (2014, p. 97) percebe que no Brasil há a tentativa de desfazer a imagem de simplicidade culturalmente marcada e associada ao produto, reforçando a relação deste com a moda; já nos Estados Unidos o produto é representado por meio do caráter versátil e originalidade das pessoas que o utilizam, buscando assim a dominação de mercado e a construção da imagem da marca no país.

"O deslocamento de enfoque existente entre as campanhas é evidente. Esse enfoque, na linguagem publicitária, pode ser chamado de approach, ou seja, a maneira usada para se alcançar um objetivo utilizando uma determinada abordagem." (NATALINO, 2014, p. 97).

Finalizando, Natalino (2014, p. 97) confirma com sua pesquisa que "para a tradução de materiais publicitários, é essencial considerar o contexto de recepção dos anúncios, isto é, o público, a cultura alvo e os fatores que influenciam direta e indiretamente na recepção desses textos e que, consequentemente, influenciam em sua produção." Além disso, "[...] um mesmo anúncio não funciona de forma semelhante quando veiculado em diferentes ambientes culturais", sendo assim, "[...] um processo de tradução focado na audiência, torna-se uma das formas de viabilizar a concretização da intenção comunicativa que deu origem ao texto, no caso dos anúncios, a promoção da marca e do produto e, consequentemente, a motivação para compra."

\section{Tradução de artigos científicos: o caso da SciELO}

A tradução de artigos científicos em Ciências Humanas no Brasil é o tema de pesquisa de doutorado de Pfau (2016).

A pesquisadora afirma que "[...] a tradução de textos acadêmicos aparece como uma prática comum nas várias áreas do conhecimento. Ainda que a tradução acadêmica aconteça em grande escala nas comunidades científicas, atualmente há poucos estudos sobre este assunto.” (PFAU, 2016). Sendo a língua inglesa - língua franca -, a língua que concede visibilidade no meio acadêmico internacional, por meio de publicações dos cientistas em periódicos internacionais. (MENEGHINI; PACKER, 2007 apud PFAU, 2016). Dessa forma, "a internacionalização da pesquisa local é o objetivo de instituições acadêmicas e de pesquisadores no mundo inteiro.” (PFAU, 2016) 
A fundamentação teórica do estudo de Pfau (2016) está amparada pela Teoria Funcionalista de Tradução com foco no propósito das traduções analisadas, bem como relaciona as categorias de análise textual dos textos fonte e alvo, cuja interface teórica é realizada com base nos Estudos Interculturais (HOFSTEDE, 1980), a qual fornece um método de analisar categorias culturais, e Holliday et al. (2004) por meio de ferramentas discursivas para captar o universo de comunidades culturais de pequena e grande escala onde os indivíduos estão inseridos (PFAU, 2016), bem como Foucault (1966; 2000), Bakhtin $(1979 ; 2011)$ e Swales (1990) para representar as Ciências Humanas na língua e Marcuschi (2008) para tratar das discussões sobre o gênero textual acadêmico.

Pfau (2016) delimita seu corpus com 12 artigos acadêmicos na área de Ciências Humanas, mais especificamente na História, Antropologia, Ciências Políticas e Estudos de Gênero. Todos os artigos estão disponíveis no portal SciELO e a análise foca no confronto de categorias culturais presentes nos textos fonte em português brasileiro e na sua tradução para a língua inglesa. (PFAU, 2016).

O objetivo geral de Pfau (2016) é

[...] perceber se os tradutores dos textos analisados mostram tendências de estratégias tradutórias neste gênero e se interferências tradutórias conscientes podem colaborar com a função informativa e argumentativa do texto de modo que a pesquisa brasileira em Ciências Humanas tenha condições de ser amplamente lida, compreendida, utilizada e citada por leitores internacionais. (PFAU, 2016).

A pesquisadora observa estratégias de tradução dentro de categorias culturais de análise levando em consideração um amplo público-alvo de leitores acadêmicos proficientes em inglês e não proficientes em português. Por meio deste procedimento, Pfau (2016) constata que a vasta maioria dos casos estudados conta com traduções literais ou empréstimos da língua fonte sem informações adicionais que levem o leitor internacional a entender uma particularidade cultural específica do texto. A minoria dos casos estudados mostra que os tradutores interferiram nessas particularidades culturais do texto causando um efeito mais explicativo ou informativo para o leitor. Pfau (2016) também atenta que interferências tradutórias tendem a cumprir melhor com as duas principais funções do gênero artigo de pesquisa acadêmico: informar e argumentar.

\section{Tradução de quadrinhos: uma proposta de modelo para tradução}

Como última interface que discutimos neste artigo, temos a proposta de unidades didáticas para a tradução de história de quadrinhos (HQs). Liberatti (2017) parte do princípio que preparar tradutores para esse gênero textual específico, além de interessante para o mercado editorial, preenche uma lacuna existente, pois pouco se pesquisa sobre a tradução específica de quadrinhos. Os poucos trabalhos desenvolvidos na área são pioneiros e, no caso específico de Liberatti, ainda muito recente.

Em sua pesquisa de doutorado, Liberatti (2017) tem como propósito a elaboração de uma proposta didática para a formação de tradutores para HQs. Para tanto se baseia na teoria funcionalista, Nord (1991), e no enfoque por tarefas de tradução do Grupo PACTE, liderado por Hurtado Albir (1996; 2007), para o par de línguas inglês-português brasileiro (tradução direta), para inserção em fases intermediárias-avançadas de cursos brasileiros

de bacharelado em Tradução. Seu foco é, portanto, didático, que visa o desenvolvimento de um modelo específico para a tradução do hipergênero quadrinhos. 
As singularidades do gênero textual conduzem a especificidades de tradução, impondo desafios ao tradutor. Com a elaboração de uma proposta didática voltada à tradução de quadrinhos, a pesquisadora contribui para a área da didática da tradução, colaborando para o enriquecimento das propostas voltadas à formação de tradutores em âmbito nacional. (LIBERATI, 2017).

Para Hurtado Albir (2011 apud LIBERATTI, 2017, p. 267), a proposta didática pode e deve ser adaptada de acordo com cada situação específica, levando em conta, entre outros fatores, as necessidades dos estudantes e o contexto de ensino. Ao expandir a temática, Liberatti (2017, p. 270, grifo nosso) afirma que

[...] o desenho de um material didático metodologicamente organizado em UDs [unidades didáticas] construídas em torno de tarefas de tradução pode utilizar das premissas funcionalistas como base de sua proposta, como fizemos em nosso próprio material didático.

Dessa forma, pode-se considerar que “[...] as tarefas de tradução são desenhadas tendo como um de seus objetivos a produção de traduções funcionalistas (ou o preparo das aprendizes para tal), enxergando o encargo e a análise textual orientada à tradução como essenciais ao tradutor de quadrinhos." (LIBERATTI, 2017, p. 270). Aqui, mais uma vez temos um exemplo de como a Teoria Funcionalista e o Modelo de Análise Textual (NORD, 1991) conversam com outras teorias e propostas didáticas.

Para alcançar seus objetivos propostos, Liberatti (2017) entrevista tradutores e editores de HQs traduzidas no contexto brasileiro para obter informações sobre o mercado de HQs traduzidas no Brasil. Com base nas respostas, Liberatti (2017) listou os desafios que os tradutores enfrentam ao traduzir HQs para o público brasileiro e tais desafios servem de guia para a elaboração do material didático aplicado em sala de aula, na disciplina Tradução e Gêneros Discursivos, no curso de bacharelado em Tradução em Língua Inglesa da Universidade Estadual de Maringá (UEM).

Ao testar sua proposta didática, Liberatti (2017) defende em seu trabalho a necessidade da oferta de disciplinas, nos cursos brasileiros de bacharelado em Tradução, voltada a gêneros textuais específicos, pois cada um deles apresenta características peculiares que exigem tratamentos diferenciados ao serem traduzidos.

A proposta didática desenvolvida na tese de Liberatti (2017) pode ser utilizada como base para outras propostas voltadas à formação de tradutores e à tradução de HQs, inspirando educadores interessados nessa interface, seja no par de línguas inglês-português, seja trabalhando com outros pares de línguas.

\section{Conclusão}

Retomando a proposta deste artigo de apresentar e elucidar algumas interfaces da tradução, concluímos que essas interfaces não só ampliam o universo dos estudos tradutórios, como mostram a importância do papel da interdisciplinaridade. A tradução, por sua natureza, deve ser vista como uma atividade interdisciplinar. Mundos teóricos e práticos se intercruzam e nos permitem reforçar o lastro de tudo que se desenvolve neste âmbito.

Segundo esse raciocínio, jornalistas, publicistas e professores são tradutores culturais, atuam como profissionais interdisciplinares e muitas vezes não têm consciência da abrangência de sua função. Por outro lado, temos ainda a interface de caráter técnico, como a área gastronômica, acadêmica e de gêneros específicos, como por exemplo, a tradução dos qua- 


\section{Conexão Letras}

drinhos. Essas especificidades técnicas ampliam os entornos culturais, pois "O que importa é que a intenção a comunicar seja realizada no texto de chegada.” (VERMEER, 1986, p. 6).

Se considerarmos que uma mesma receita culinária pode estar inserida na mesma língua e não é compreendida por todos os leitores, só podemos concluir que as diferenças estão na inserção cultural. Da mesma forma, tomemos os artigos científicos. Se o resumo passa por tradução restrita, quase literal, o artigo perde em riqueza de informações no que tange a cultura de origem. Como bem lembra Vermeer (1986, p. 7): "A tradução literal torna o texto mais distanciado do leitor de chegada do que o era para o leitor de partida."

Já na tradução de quadrinhos, constatamos a perda de efeito, quando a cultura não é contemplada.Resgatando as pesquisas apresentadas, observamos que abordagens teóricas diferentes nos conduzem a reflexões mais amplas, como por exemplo, que o português brasileiro e o lusitano na pesquisa de Aio (2011) são tratados como línguas diferentes e, na pesquisa de Abreu (2014), a língua alemã é tratada como sendo pluricêntrica, ou seja, uma mesma língua, disposta em diversos centros, os quais são denominados de variedades nacionais e regionais, sendo que as variedades nacionais se convergem a um centro que é considerado como compartilhador das variedades nacionais tratadas.

Polchlopek (2011) trata os títulos de fatos noticiosos como uma forma de tradução e Sachet (2005) e Mazzuti (2011) abordam uma revista de circulação mundial como um fenômeno de reflexo cultural que sofre mudanças dependendo do público para ao qual está destinada.

Diante das pesquisas e suas interfaces com a tradução apresentadas neste artigo, reforçamos que "[...] nenhuma comunicação começa num ponto zero. Há sempre toda uma série de circunstâncias, razões e motivos que levam uma pessoa a procurar o contato com outra. Há sempre o 'contínuo dos mundos possíveis'.” (VERMEER, 1986, p. 12).

Traduzir é comunicar, comunicar é interagir, e interagir é encontrar culturas.

\section{Referências}

AIO, Michelle de Abreu. O Caso AF447: o jornalista como tradutor de fatos nas culturas brasileira e portuguesa. 2011. 136 p. Dissertação (Mestrado)-Universidade Federal de Santa Catarina, Centro de Comunicação e Expressão, Programa de Pós-Graduação em Estudos da Tradução, Florianópolis: 2012.

ABREU, Juliana de. Receitas culinárias alemãs e austríacas no foco da tradução cultural: uma análise funcionalista. 2014. 132 p. Dissertação (Mestrado)-Universidade Federal de Santa Catarina, Centro de Comunicação e Expressão, Programa de Pós-Graduação em Estudos da Tradução, Florianópolis: 2014.

ESSER, Frank. Die Kräfte hinter den Schlagzeilen: Englischer und deutscher Journalismus im Vergleich. Freiburg: Verlag Karl Alber,1998.

HESSMANN, Gabriela. Tradução jornalística: alusões na tradução como fator cultural no texto telejornalístico. 2013. 106 p. Dissertação (Mestrado)-Universidade Federal de Santa Catarina, Centro de Comunicação e Expressão, Programa de Pós-Graduação em Estudos da Tradução, Florianópolis: 2013.

LAIÑO, Maria José. Multiculturalismo: propostas de recontextualizações de fatos culturais na tradução de textos em livros didáticos. 2010. 99 p. Dissertação (Mestrado)-Universidade Federal de Santa Catarina, Centro de Comunicação e Expressão,Programa de Pós-Graduação em Estudos da Tradução, Florianópolis: 2010. 
LIBERATTI, Elisângela. Traduzindo histórias em quadrinhos: proposta de unidades didáticas com enfoque funcionalista e baseadas em tarefas de tradução. 2017. 307 p. Tese (Doutorado)-Universidade Federal de Santa Catarina, Centro de Comunicação e Expressão, Programa de Pós-Graduação em Estudos da Tradução, Florianópolis: 2017. MAZUTTI, Sandra. Marcas culturais em interface: os caminhos de aproximação entre tradução e jornalismo. Florianópolis, 2011. 185 p. Dissertação (Mestrado)-Universidade Federal de Santa Catarina, Centro de Comunicação e Expressão, Programa de Pós-Graduação em Estudos da Tradução, Florianópolis: 2011.

MELO, Noemi Teles de. Texto e contexto na construção de sentidos: a tradução em sala de aula de LE. 2012. 154 p. Dissertação (Mestrado)-Universidade Federal de Santa Catarina, Centro de Comunicação e Expressão, Programa de Pós-Graduação em Estudos da Tradução, Florianópolis: 2012.

NATALINO, Laís Gonçalves. Tradução e persuasão: a tradução publicitária sob o viés funcionalista. 2014. 113 p. Dissertação (Mestrado)-Universidade Federal de Santa Catarina, Centro de Comunicação e Expressão, Programa de Pós-Graduação em Estudos da Tradução, Florianópolis: 2014.

NORD, Christiane. Text analysis in translation: theory, methodology, and didactic application of a model for translation-oriented text analysis. Amsterdam: Atlanta: 1991.

. Textanalyse und Übersetzen: Theoretische Grundlagen, Methode und didaktische Anwedung einer übersetzungsrelevanten Textanalyse. 4. ed. Tübingen: Julius Gross Verlag Brigitte Narr, 2009.

. Análise textual em tradução: bases teóricas, métodos e aplicação didática. Tradução Meta Elisabeth Zipser et al. São Paulo: Rafael Copetti Editor, 2016.

PFAU, Monique. Cultural translation in the human sciences: brazilian case studies. 2016. 541 p. Tese (Doutorado)-Universidade Federal de Santa Catarina, Centro de Comunicação e Expressão, Programa de Pós-Graduação em Estudos da Tradução, Florianópolis, 2016.

POLCHLOPEK, Silvana Ayub. O mundo pós 11 de setembro: tecendo fios/textos entre a tradução e a narratividade jornalística. 2011. 324 p. Tese (Doutorado)-Universidade Federal de Santa Catarina, Centro de Comunicação e Expressão, Programa de Pós-Graduação em Estudos da Tradução, Florianópolis: 2011.

REISS, Katharina. Textyp und Übersetzungsmethode: Der operativ Text. Heidelberg: Julius Groos Verlag, 1983.

SACHET, Sabrina. A interface tradução e jornalismo: marcas culturais no texto de revista. 2005. Dissertação (Mestrado)-Universidade Federal de Santa Catarina, Centro de Comunicação e Expressão, Programa de Pós-Graduação em Estudos da Tradução, Florianópolis: 2015.

VERMEER, Hans J. Esboço de uma teoria da tradução. Porto: Edições ASA, 1986. ZIPSER, Meta Elisabeth. Do fato à reportagem: as diferenças de enfoque e a tradução como representação cultural. 2002. Tese (Doutorado)-Universidade de São Paulo, Faculdade de Filosofia, Letras e Ciências Humanas, São Paulo: 2002. 